\title{
Factors Affecting the Adoption and Usage of Luggage Tracking System by Public Transporters Based on TAM Model
}

\author{
George Kasanga1, Jackson Phiri² \\ ${ }^{1}$ Department of Electrical and Electronics Engineering, School of Engineering, University of Zambia, Lusaka, Zambia \\ ${ }^{2}$ Department of Computer Science, School of Natural Science, University of Zambia, Lusaka, Zambia \\ Email:ygkasanga@gmail.com, Jackson.phiri@cs.unza.zm
}

How to cite this paper: Kasanga, G. and Phiri, J. (2020) Factors Affecting the Adoption and Usage of Luggage Tracking System by Public Transporters Based on TAM Model. Open Journal of Business and Management, 8, 855-865.

https://doi.org/10.4236/ojbm.2020.82052

Received: January 26, 2020

Accepted: March 20, 2020

Published: March 23, 2020

Copyright (๑) 2020 by author(s) and Scientific Research Publishing Inc. This work is licensed under the Creative Commons Attribution International License (CC BY 4.0).

http://creativecommons.org/licenses/by/4.0/

\begin{abstract}
Technology has revolutionized communication, and how services can be delivered to the intended end-users. Many areas such as supply chain, logistics, health, aviation, and education have been greatly influenced. Despite all the technological advancements, public transportation in Zambia, which is dominated by bus operators, still faces challenges in computerizing and automating their business processes, to improve service delivery. The problem of misplaced and missing luggage is among the problems the operators are currently facing. The first objective was to identify the challenges faced by bus operators in managing passenger luggage and factors that affect the adoption of technology. A population of bus operators and passengers was identified, of which a sample was conveniently drawn from the intercity bus terminus. Technology Adoption Model (TAM) was used in this research to guide the development of questionnaires, interviews and observations, in order to understand the business processes and operations. Results from the study show a link between the use of technology in managing passengers' language, ease of use and usefulness of the technology. Furthermore, the results show that $28 \%$ of the sample population misplaced or lost luggage during a journey. Most participants in the research expressed willingness to use a system that can allow for real-time monitoring of luggage, with a few expressing security concerns of a system that is connected to the internet. The study recommends the development of luggage tracking system based on RFID, GPS and GSM technologies with a GUI to aid bus operators in managing passenger luggage, which will improve accountability and reduce lost customer luggage incidences.
\end{abstract}

\section{Keywords}

Public Transport, Luggage Tracking, TAM, RFID, GPS, Web Technologies 


\section{Introduction}

Zambia has embarked on road network infrastructure development, for example, the link Zambia 8000 Project [1], and many other road expansions countrywide. This has attracted many bus operators to provide the service, to meet the growing demand. In 2018 about 519,817 tourists are recorded to have visited various tourist destinations in the Lusaka from across the country and the region [2]. The most common type of road transport is by bus. InterCity Bus Terminus has been the largest station constructed to meet the growing number of travellers, as it is centrally located.

According to the RTSA annual report [3], the number of bus operators has increased to over 300. It is also worth noting that among these operators only 5 are using a computerized bus ticketing system provided by Afro-bus. When further investigating, the available solution has not been used for online bus reservation and did not have a module for luggage tagging and tracking. Passenger luggage can be classified into a light and heavy luggage, light luggage being handheld luggage that can be handbags, bag packs, and any small packages that can be fitted inside the bus. Heavy luggage is therefore considered as any package that can be placed in the luggage compartment of the bus. Most travellers carry with them sentimental items, and expensive merchandise on journeys; however, bags get misplaced, lost and worst-case stolen at bus stations. For this reason, it is very necessary to have a mechanism to track luggage in case of loss or theft. Another noticeable development is the advent of courier services provided as an add-on service by bus operators; customers entrust their merchandise and parcels with bus operators for delivery to the rightful owner.

The rest of the paper is arranged as follows: we consider the theoretical framework, the literature review and related works; we then outline the methodology used in the study; results from the data collected are presented and discussed; finally the conclusion.

\section{Theoretical Framework}

There are several models existing that have been utilized to explore Technology adoption. Most investigations concentrating on the acceptance of information systems or technologies have their foundations in Technology Acceptance Model (TAM) initially proposed by Davies in 1986 [4]. The model is intended to predict the user's acceptance of Information Technology and usage in an organizational context. TAM focuses on the attitude explanations of intention to use a specific technology or service. Other models such as Theory of Reasoned Action (TRA), Theory of Planned Behavior (TPB), Innovation Diffusion Theory (IDT) and the extension TAM models TAM2, TAM3, unified theory of acceptance and usage of technology (UTAUT).this study makes use of TAM in order to understand the factors affecting the adoption of luggage tracking systems by public transporters. 


\subsection{TAM Model}

The model in Figure 1 is adapted from a study that was conducted in Zambia to establish the adoption of E-tax returns by Zambia revenue authority, which has three factors, Perceived Ease of Use (PEU) defined as the degree to which a person believes that using a particular system would be free of effort [4], Perceived Usefulness (PU) defined as the degree to which a person believes that using a particular system would enhance his or her performance, Perceived Risk (PR) Perceived risk is defined as a consumer's perceptions of the uncertainty and the possible undesirable consequences of buying a product or service [4]. Indeed, people may feel a certain degree of risk when using an Internet-based channel because perceived risk has the characteristics to increase vulnerabilities and generate inhibiting aspects to consumers.

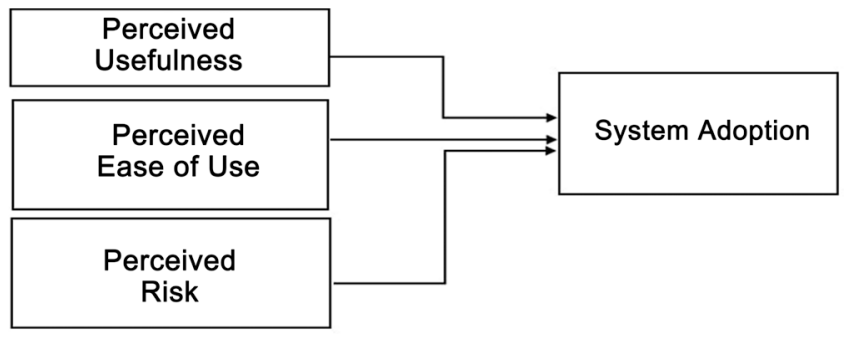

Figure 1. TAM model [5].

\subsection{Literature Review}

[6] had presented a new strategy for control of baggage handling systems based on Intelligent Transportation Systems. Here three main control issues in baggage handling system, routing and scheduling problem, empty cart management, and line balancing are identified and a combined control approach based on model predictive control is proposed. The control approach can be formulated as a linear programming problem that can be solved efficiently, and hence can be extended to a large scale handling system.

[7] had proposed design of baggage tracing and handling system which uses smart RFID and IoT which is based on a cloud server. It has a designed prototype at two locations having both check-in and check-out processes. A more secured algorithm is used for generating tags that are attached to printed baggage label with the details of passenger and airline stored in it and RFID Readers in the check-out areas facilitate step tracking of baggage which prevent baggage loss. The proposed system ensures less consumption of time, security for baggage.

[8] had proposed design for luggage management which uses RFID tags to enhance the ability for baggage tracking, dispatching and conveyance, so as to improve management efficiency and the user's satisfaction. It uses an intelligent RFID Reader which has the ability of data disposal and provides edge savant service is presented. The prototype readers and its experiment in the airport baggage handling system are also introduced in this proposed model.

Konas bags offer luggage and bag packs that we can track from the smartphone. 
With the help of the tracking device present in the bag, we can track the device through the application installed in the smartphone [9]. The tags don't provide you with a mobile or computer frontend interface to track and view the location of the bag, instead, the company owning the tag would try to track down the location. A lot of trackable tags are available which can be tied with the bag in order to track the bags when they are lost. These tags have an inbuilt GPS chip through which the company would track the lost bag. There are a lot of companies in the market who are providing these tags with different features like dynotag, LugLoc and Robot Check [10].

Trackdot is a luggage tracker device which is placed inside the bag when a person is travelling. It works on ground-based cellular technology and microelectronics. When in an aeroplane during takeoff, it shuts down automatically and enters in an aeroplane mode and again activates during landing when the pilot applies brakes [11].

\section{Methodology}

A Mixed Methods Research Methodology comprises a combination of qualitative and quantitative research types [12]. Mixed Methods Research Methodology combines diverse types of data which provides the best understanding of a research problem. A survey was conducted to understand the factors affecting technology adoption based on TAM.

The study population included members of staff from the Lusaka City Council, Bus Operators, Passengers and Drivers. The study was conducted in Lusaka, at our intercity bus terminus. The study employed a mathematical formula to correctly come up with a suitable Sample for the study. The ideal sample for infinite populations as outlined by (Cochran, 1977) is given as no $=\left(z^{2} \times p(1-p)\right) / e^{2}$

$$
\text { No }=\left(1.96^{2} \times 0.5(1-0.5)\right) /\left((0.06)^{2}\right)=267
$$

\section{Data Collection}

Before collection of data, the questionnaire was piloted on a subset of the target population to test for data consistency. Once the questionnaire was refined it was used collecting data from the targeted population who are bus operators and passengers within Lusaka city. The data collection was conducted in 8 weeks. A descriptive research design was used in describing the current state of affairs, the research employed a mixed-methods approach, which is a combination of both qualitative and quantitative methods. The study used Purposive sampling and convenient sampling.

SPSS was used to analyze the data collected. Spearman's correlation coefficient and P-values were used in the statistical analysis of the results.

\section{Results and Discussion}

In this section, the results from the baseline study derived from the analysis of 
each variable through descriptive statistics are presented. The presentation of the results is in the form of tables, bar charts and pie charts.

\subsection{Demographics Data}

Data were collected from 198 respondents, The questionnaire respondents were as shown in Figure 2: 116 (58\%) were male participants, 82(42\%) were female participants.

On age distribution, it was found that nine (9) respondents were 20 years and below representing 4.55 per cent of the respondents. One hundred and twelve (112) of the respondents came from the 21 - 30 age group indicating 56.57 per cent and fifty (50) respondents from 31 - 40 age groups corresponding to 25.25 per cent. Furthermore, seventeen (17) respondents representing 8.59 per cent came from $41-50$ age groups. Five (5) respondents representing 2.53 per cent came from 51 - 60 age groups. The last age group of 61 and above represented five per cent of the respondents. The information on age was crucial because it helped the researcher to know the computer literacy levels and how easily respondents would be able to learn computers to effectively use the luggage tracking system. We got the most feedback from the age group $21-30$ as shown in Figure 3.

\section{RESPONDENTS GENDER}

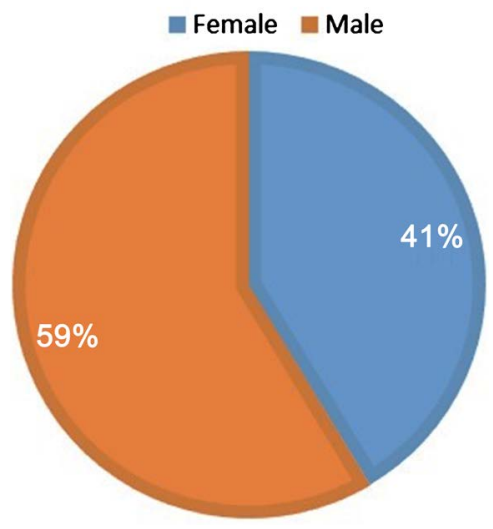

Figure 2. Gender of respondents.

\section{DISTRIBUTION OF RESPONDENTS BY AGE}

112

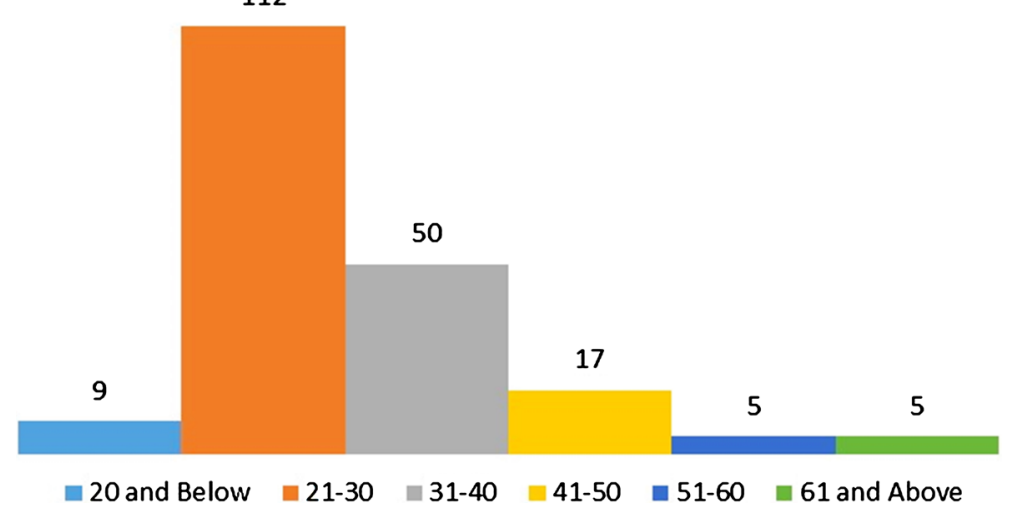

Figure 3. Age of respondents. 


\subsection{Travelling Experience}

When respondents were asked if they had made use of public transportation when travelling from town to another, the study reviewed that 99.5 per cent of the respondents have used public transportation with only 0.5 per cent had not used these services as shown in Figure 4.

The findings of misplaced and lost luggage are shown in Figure 5 as passengers make use of public transportation, 55 of the respondents representing 28 per cent confirmed to have experienced an incident of missing or lost luggage while 72 per cent had not lost or misplaced luggage.

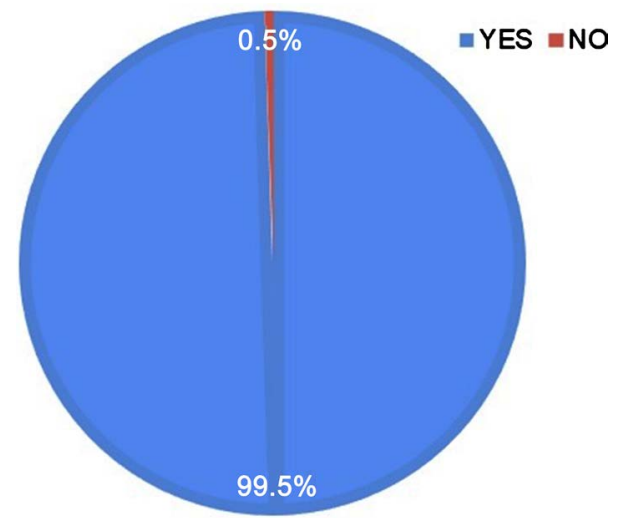

Figure 4. Usage of bus transportation.

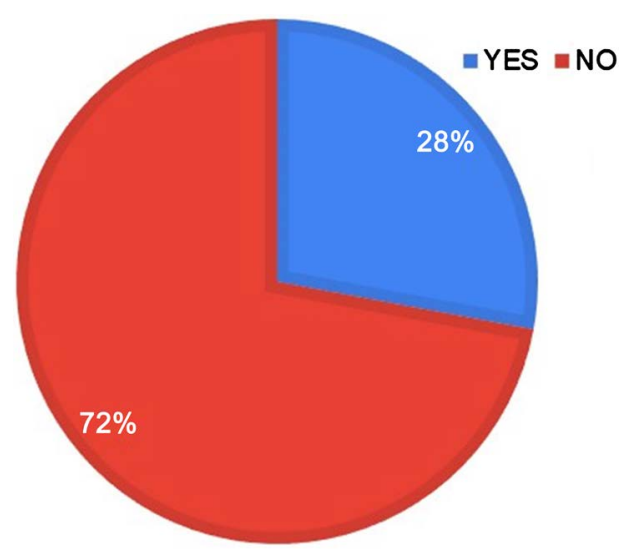

Figure 5. Lost or misplaced luggage on a journey by passengers.

\subsection{Passenger Luggage Tracking Adoption Factors}

\section{Perceived Usefulness (PU)}

I think the system would make it easier to monitor my luggage.

I think cases of missing luggage can easily be settled.

I think using the system can help bus operators identify owners of missing luggage.

I think using the system would improve the performance of courier services.

\section{Perceived Ease of Use (PEU)}

I think that interaction with a luggage tracking system is clear and easily un- 
derstandable.

I think it's easy to become skillful at using the luggage tracking system.

I would find tracking my luggage progress with the system to be flexible to interact with.

I think that learning to operate a luggage tracking system is easy for me.

\section{Perceived Risk (PR)}

I think using the system puts my privacy at risk.

I think using the system in tracking luggage has potential security risks.

I think bus operators adaption to change and startup cost can prevent usage.

I think using the system connected to the internet has the potential of being hacked.

The study reviewed that $98.4 \%$ of the respondents felt the luggage tracking feature is useful, as depicted in Figure 6, for the improvement of service delivery when the proposed workflow of proposed system was explained, Figure 7 shows $88.7 \%$ of the respondents felt that the system was easy to learn and operate, $75.4 \%$ of the respondents as shown in Figure 8 had concerns that factors such as privacy, security and unwillingness to invest in technology can affect the adoption of the system.

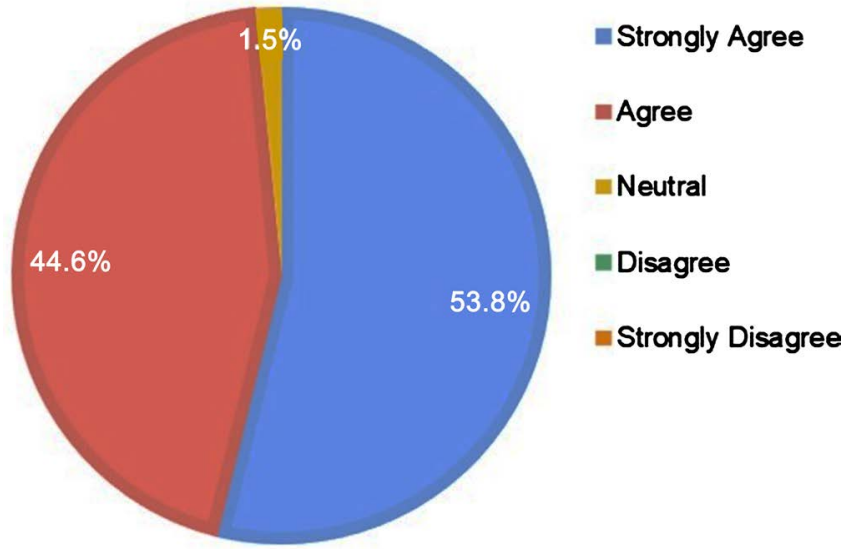

Figure 6. Perceived usefulness (PU).

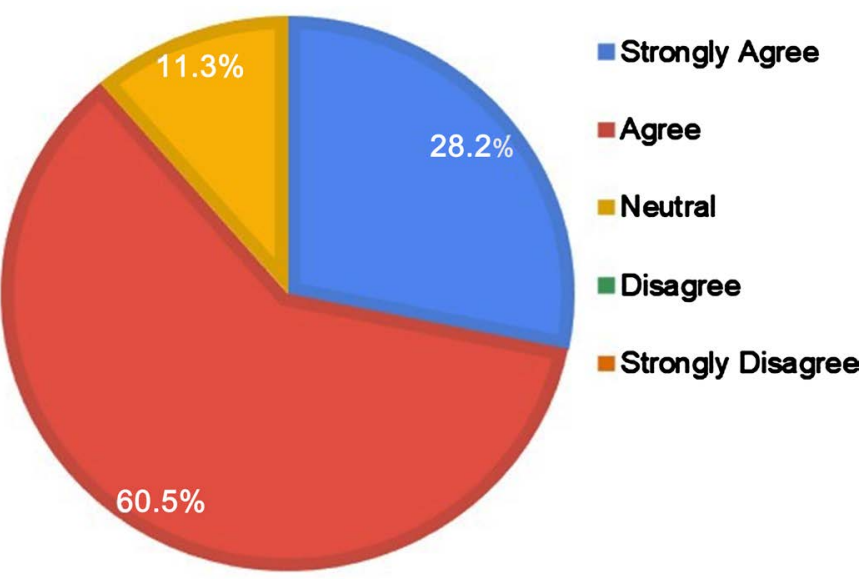

Figure 7. Perceived ease of use (PEU). 


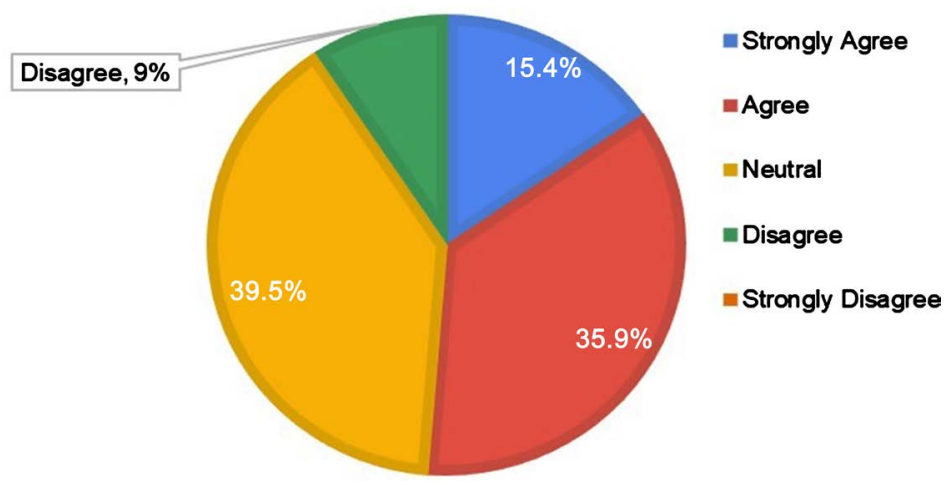

Figure 8. Perceived risk (PR).

\subsection{Statistical Significant (P-Values)}

All hypothesis tests ultimately use a P-value to weigh the strength of the evidence (what the data is telling you about the population). The P-value is a number between 0 and 1 and interpreted in the following way:

- A small P-value (typically $\leq 0.05$ ) indicates strong evidence against the null hypothesis, so you reject the null hypothesis.

- A large P-value (>0.05) indicates weak evidence against the null hypothesis, so you fail to reject the null hypothesis.

- P-values very close to the cutoff (0.05) are considered to be marginal (could go either way).

From this study, we are able to see that the P-value is $(\mathrm{p}<0.01)$ as shown in Figure 9 which rejects the Null hypothesis, that states ease of use, usefulness and risk do not affect the adoption

The correlation coefficient between perceived ease of use factors of the tracking system and perceived usefulness of the tracking system factors range from $0.133-0.547$ at $(p<0.01)$. Figure 9.suggests that there is a substantial positive relationship between respondents' perceived ease of use and perceived usefulness of the tracking system.

\section{Significance of the Study}

The study provides a base to understand the operational challenges faced by bus operators and the service expectations of passengers, it also reviews the public perception of how technology can be used transform luggage management at bus stations, the results of the study highlighted Technology adoption factors and helped in developing a prototype system to help operators in monitoring passenger's valuable luggage, providing a means to track luggage improves accountability and reduces lost customer luggage incidences.

\section{Limitations}

The study only focused on intercity bus terminus located in Lusaka, smaller Bus Stations for inter-town routes in other provinces and districts could not be surveyed as we were hindered by time, logistics and financial limitations. 


\begin{tabular}{|c|c|c|c|c|c|c|c|c|c|c|}
\hline & & & PUF1 & PUF2 & PUF3 & PUF4 & PEUF1 & PEUF2 & PEUF3 & PEUF4 \\
\hline \multirow[t]{24}{*}{ Spearman's rho } & \multirow[t]{3}{*}{ PUF1 } & Correlation Coefficient & 1.000 & $.306^{*}$ & .425 & $.4799^{-}$ & .386" & 277 & $.252^{*}$ & .300 \\
\hline & & Sig. (2-tailed) & & .000 & .000 & .000 & .000 & .000 & .000 & .000 \\
\hline & & $\mathrm{N}$ & 197 & 197 & 197 & 197 & 197 & 197 & 197 & 197 \\
\hline & \multirow[t]{3}{*}{ PUF2 } & Correlation Coefficient & $.306^{\circ}$ & 1.000 & $284^{\circ}$ & $.297^{*}$ & $.231^{\circ}$ & .130 & $.317^{*}$ & $.223^{\prime \prime}$ \\
\hline & & Sig. (2-tailed) & .000 & & .000 & .000 & .001 & .068 & .000 & .002 \\
\hline & & $\mathrm{N}$ & 197 & 197 & 197 & 197 & 197 & 197 & 197 & 197 \\
\hline & \multirow[t]{3}{*}{ PUF3 } & Correlation Coefficient & $.425^{\circ}$ & $.284^{\circ}$ & 1.000 & $.419^{\circ}$ & $348^{\circ}$ & $249^{\circ}$ & $.266^{\circ}$ & .311" \\
\hline & & Sig (2-tailed) & .000 & .000 & & .000 & .000 & .000 & .000 & .000 \\
\hline & & $\mathrm{N}$ & 197 & 197 & 197 & 197 & 197 & 197 & 197 & 197 \\
\hline & \multirow[t]{3}{*}{ PUF4 } & Correlation Coefficient & $.479^{\circ}$ & $297^{\circ}$ & $419^{*}$ & 1.000 & $429^{\circ}$ & $368^{*}$ & $.280^{\circ}$ & $334^{*}$ \\
\hline & & Sig. (2-tailed) & .000 & .000 & .000 & & .000 & .000 & .000 & .000 \\
\hline & & $\mathrm{N}$ & 197 & 197 & 197 & 197 & 197 & 197 & 197 & 197 \\
\hline & \multirow[t]{3}{*}{ PEUF1 } & Correlation Coefficient & $.386^{\circ}$ & $.231^{\circ}$ & $348 \cdots$ & $.429^{\circ}$ & 1.000 & .509 & $.480^{\circ}$ & $.547^{\prime \prime}$ \\
\hline & & Sig. (2-tailed) & .000 & .001 & .000 & .000 & & .000 & .000 & .000 \\
\hline & & $\mathrm{N}$ & 197 & 197 & 197 & 197 & 197 & 197 & 197 & 197 \\
\hline & \multirow[t]{3}{*}{ PEUF2 } & Correlation Coefficient & $277^{\circ}$ & .130 & $249^{*}$ & $.368^{* \prime}$ & $.509^{\circ}$ & 1.000 & $.449^{\circ}$ & $455^{\circ}$ \\
\hline & & Sig. (2-tailed) & .000 & .068 & .000 & .000 & .000 & & .000 & .000 \\
\hline & & $\mathrm{N}$ & 197 & 197 & 197 & 197 & 197 & 197 & 197 & 197 \\
\hline & \multirow[t]{3}{*}{ PEUF3 } & Correlation Coefficient & .252 & $3177^{\prime \prime}$ & 266 & $280^{\circ}$ & $.480^{\circ}$ & .449" & 1.000 & .511 \\
\hline & & Sig. (2-tailed) & .000 & .000 & .000 & .000 & 000 & .000 & & .000 \\
\hline & & $\mathrm{N}$ & 197 & 197 & 197 & 197 & 197 & 197 & 197 & 197 \\
\hline & \multirow[t]{3}{*}{ PEUF4 } & Correlation Coefficient & $.300^{\circ}$ & $.223^{\prime \prime}$ & $311^{\circ}$ & $.334^{*}$ & $.547^{\circ}$ & $.455^{\circ}$ & $.511^{-1}$ & 1.000 \\
\hline & & Sig. (2-tailed) & .000 & .002 & .000 & .000 & .000 & .000 & .000 & \\
\hline & & $\mathbf{N}$ & 197 & 197 & 197 & 197 & 197 & 197 & 197 & 197 \\
\hline
\end{tabular}

${ }^{*}$. Correlation is significant at the 0.01 level (2-tailed).

Figure 9. Correlation between perceived usefulness and ease of use.

\section{Conclusions}

In this study, we conducted a baseline study to establish the challenges faced by Passengers and Bus Operators in adopting new technologies to improve service delivery. Questionnaires were used to collect the quantitative data needed for the baseline study. A detailed literature review was conducted to find existing RFID applications in object tracking, monitoring and luggage management. The literature review also covered the workings and characteristics of RFID systems, the integration of RFID, WSNs and Databases, and software development methodologies. Qualitative data were obtained from interviews conducted with operational managers for different bus operators to understand the business process.

Bus operators face challenges in the effective handling, monitoring and tracking of passenger and parcels. This manual process involves the use of a ticket to be used as means of validating ownership of luggage; however, challenges arise when the ticket is misplaced, also keeping a record of the passenger manifest is all paper-based which can easily be misplaced and destroyed. Most of the bus operators are providing the courier service that members of the public can use to send and receive goods and parcels from all parts of the country. The current mode of operation doesn't allow for the client to receive notification or look up parcel delivery information from the convenience of their phone or computer; 
the current methods are prone to human errors, inefficient use of time, and inaccuracies. From the literature review presented, the results obtained from the baseline study and the system prototype, it is clear that a sensor-based automated RFID luggage management system can provide a more accurate, convenient, and rapid method of identifying and managing parcels and luggage at bus stations.

\section{Acknowledgements}

The authors of this paper would like to thank and acknowledge all those who helped and took part in the providing of information required for the study.

\section{Conflicts of Interest}

The authors declare no conflicts of interest regarding the publication of this paper.

\section{References}

[1] Embassy of the Republic of Zambia in Washington DC (2019) Seventh National Development Plan 2017-2021.

http://www.zambiaembassy.org/document/seventh-national-development-plan-201 $7-2021$

[2] Zambia: Zambia Records an Influx of Tourists at Different Sites. https://www.lusakatimes.com/2018/09/13/zambia-records-an-influx-of-tourists-atdifferent-sites/

[3] https://www.rtsa.org.zm/wp-content/uploads/2019/09/RTSA-ANNUAL-REPORT-2 018.pdf

[4] Venkatesh, V., Morris, M., Davis, G. and Davis, F. (2003) User Acceptance of Information Technology: Toward a Unified View. MIS Quarterly, 27, 425-478.

[5] Soneka, P. and Phiri, J. (2019) A Model for Improving E-Tax Systems Adoption in Rural Zambia Based on the TAM Model. Open Journal of Business and Management, 7, 908-918.

[6] Bencini, L., Chiti, F., Collodi, G., Di Palma, D., Fantacci, R., Manes, A. and Manes, G. (2009) Agricultural Monitoring Based on Wireless Sensor Network Technology: Real Long Life Deployments for Physiology and Pathogens Control. 2009 Third International Conference on Sensor Technologies and Applications, Athens, Glyfada, 18-23 June 2009.

[7] Singh, A., Meshram, S., Gujar, T. and Wankhede. P.R. (2016) Baggage Tracing and Handling System Using RFID and IoT for Airports. 2016 International Conference on Computing, Analytics and Security Trends (CAST), Pune, 19-21 December 2016, 466-470.

[8] Ouyang, Y., Hou, Y., Pang, L., Wang, D. and Xiong, Z. (2008) An Intelligent RFID Reader and Its Application in Airport Baggage Handling System. 2008 4th International Conference on Wireless Communications, Networking and Mobile Computing, Dalian, 12-14 October 2008, 1-4.

[9] http://thegadgetflow.com/portfolio/konas-theworlds-only-trackable-luggage-and-ba ckpacks/

[10] https://flipboard.com/@anyajones2014/top-10-best-smart-luggage-tracker-device-re 
views-2016-5khet719y

[11] https://www.trakdot.com/en/how-it-works

[12] Kothari, C.R. (2004) Research Methodlogy: Methods and Techniques. 2nd Edition, New Age International (P) Ltd., New Delhi. 